\section{A Simple Homemade Carbon Dioxide Delivery System for Endovascular Proce- dures in the Iliofemoral Arteries}

\section{To the Editor:}

We read the article by Kawasaki et $\mathrm{al}^{1}$ with great interest and were very pleased to see the disclosure of the carbon dioxide $\left(\mathrm{CO}_{2}\right)$ angiography technique for iliofemoral disease.

We have been developing in Brazil since 2011 a similar project to compare the use of $\mathrm{CO}_{2}$ and iodinated contrast for treatment of not only conventional aortoiliac stenosis, but also femoropopliteal disease and infrarenal aortic aneurysms.

The results presented by our colleagues are extraordinary; however we have considerations to make regarding the technique used for aspiration of the $\mathrm{CO}_{2}$ contrast, because the described procedure is associated with a high chance of contamination with room air, even though there have been no complications in this series so far.

At the time the surgeon withdraws his finger from the 3-way stopcock, within a fraction of a second, contact unavoidably occurs between ambient air and the $\mathrm{CO}_{2}$ inside the syringe. The simple removal of $5 \mathrm{ml}$ from the end section of the syringe does not safely guarantee elimination of the contaminated air, because it mixes with the $\mathrm{CO}_{2}$ contents. This way, small amounts of ambient air are inevitably injected into the patient's arterial circulation.

To avoid this contamination, we use a simple and practical artifice that works effectively with good results. We have refined a technique previously describedby Cronin et al, ${ }^{2}$ also based on a "home made" system that does not require the use of injection pumps and is safer than the method proposed by Kawasaki et al because air does not come in contact with the $\mathrm{CO}_{2}$.

Similar to the method described by Cronin et al, we use a cylinder with medicinal $\mathrm{CO}_{2}$, a particle filter and a 3-way stopcock and the entire $\mathrm{CO}_{2}$ aspiration procedure is performed inside a bowl of saline solution. After capturing the required volume of $\mathrm{CO}_{2}$, an additional $3-5 \mathrm{ml}$ of saline solution is aspirated into the syringe to provide a water seal when the tip is kept down. This way, a physical barrier is created between the room air and $\mathrm{CO}_{2}$ contents, which is independent of manual compression and safe from air contamination.

We believe this technique is a cheap and easily reproducible alternative, particularly useful in patients with renal impairment or iodinated contrast hypersensitivity. We have satisfactorily used this method in more than 30 cases, confirming its validity.

We greatly enjoyed reading the article by Kawasaki et al and believe this technique makes an important contribution towards endovascular surgery.

\section{References}

1. Kawasaki D, Fujii K, Fukunaga M, Masutani M, Nakata A, Masuyama T. Safety and efficacy of endovascular therapy with a simple homemade carbon dioxide delivery system in patients with ileofemoral artery diseases. Circ J 2012; 76: $1722-1728$.

2. Cronin P, Patel JV, Kessel DO, Robertson I, McPherson SJ. Carbon dioxide angiography: A simple and safe system of delivery. Clin Radiol 2005; 60: 123-125.

Cynthia de Almeida Mendes, MD Department of Vascular Surgery, Hospital Israelita Albert Einstein, São Paulo, Brazil

Nelson Wolosker, MD, PhD

Department of Vascular Surgery, Hospital Israelita Albert Einstein, and Division of Vascular Surgery, Hospital das Clínicas, University of São Paulo Medical School, São Paulo, Brazil

Mariana Krutman, MD

Hospital Israelita Albert Einstein, São Paulo, Brazil

(Released online November 28, 2012) 